Iszaj, F., Ehmann, B., Griffiths, M.D. \& Demetrovics, Z. (2017). A qualitative study on the effects of psychoactive substance use upon artistic creativity. Substance Use and Misuse, https://doi.org/10.1080/10826084.2017.1404103

\begin{abstract}
Background: Psychoactive substance use has often been claimed to help generate and facilitate the artistic creative process. Aims: The present study explored the role of artists' substance use in their creative processes and their efforts to balance between enhancement and relaxation. Methods: Semi-structured interviews concerning the artistic creative process and the role of psychoactive substance use were recorded with 72 artists and analyzed using content analysis. The participants were classified according to their substance use in three groups (Cannabis Group, Alcohol Group, and Control Group). Results: Results show that both alcohol and cannabis were used to facilitate creativity and the emotional states that are necessary for the artistic creative process. Participants in the Control group reported that listening to music might function as a mind-altering tool. It was also found that for some artists, substance use is not only characteristic to creation, but it is also part of their everyday lives. Conclusion: Artists are aware of the balancing phenomenon during the artistic creative process. Whether psychoactive substance(s) or other environmental stimuli (such as music) are used to reach the required effect appears to depend upon the individual.
\end{abstract}

Keywords: creativity; artist; psychoactive substance use; alcohol; cannabis; music 


\section{A qualitative study on the effects of psychoactive substance use upon artistic creativity}

\section{INTRODUCTION}

\section{The artistic creative process and the 'balancing' phenomenon}

Artistic creative work is defined by Kris (1962) as having two phases, the "inspirational" and the "elaborational" phase. The "inspirational" phase provides the basis of artwork dominated by unconscious and preconscious functioning and is accompanied with the feeling of being driven. This phase was defined by Kris as having similarities with regressive processes referring to such impulses and drives that can be difficult to attain in the normal conscious state. In contrast to the regressive and ecstatic nature of the inspirational phase (Kris, 1939), the second phase is characterized by ego functions because concentration, purposive planning, and the analysis of reality are needed. The unconscious inputs that the artist passively receives in the first phase, are transformed into a "digestible" (i.e., more conscious) form during the second phase.

Ehrenzweig's (1970) phenomenon, "the hidden order of art" refers to the ability that disappears from most adults but which artists might maintain because of their enhanced sensitivity. In this state, knowledge, feelings, cognitive, and affective processes are not yet differentiated and have been compared to childlike and regressive states. Consequently, artists might use psychoactive substances in order to recall the earlier states of knowledge and feelings - to facilitate the regressive state. Knafo (2008) states that possible reasons for artists' substance use might be the search for experiences of depersonalization and derealization that can help loosen reality experiences and achieve altered perceptual states. This intention is described as the regressive reliving of earlier self-states and object relations (Knafo, 2008). 
Furthermore, working with conscious and unconscious stimuli implies that the artist is subject of emotional fluctuations that are elements of the creative act. The balancing effect of psychoactive substances (Iszáj \& Demetrovics, 2011) refers to this phenomenon, namely that because of artists' heightened sensitivity and emotional stress, they are more likely to use psychoactive substances. In a previous study, the balancing role of opium was examined through the analysis of the life and artistic work of Edgar Allan Poe and Samuel Taylor Coleridge (Iszáj \& Demetrovics, 2011).

\section{Psychological effects of alcohol upon artistic creativity}

Alcohol is a psychoactive substance that has a depressant effect on the central nervous system. It reduces inhibitions and eases anxiety. The long-term effects of alcohol use might cause changes in personality, enhanced anxiety and mood fluctuation can emerge (Cohen, 1995). Furthermore, heavy use of alcohol is linked to depression, psychological distress, suicidal thoughts, and/or emotional instability (Sher, 2006).

The association between alcohol use and creativity and the artistic creative process is unclear from reviews of the literature (see Iszaj, Griffiths \& Demetrovics [2016] for a recent overview). Tolson and Cuyjet (2007) assert that heavy alcohol use is very common among jazz musicians. There are case studies on the topic such as the effects of alcohol and opiates in the life of Edgar Allan Poe who used both psychoactive substances heavily throughout his life (Iszáj \& Demetrovics, 2011). Additionally, Belli (2009) published a case study about the musician Brian Wilson (of US group the Beach Boys) and demonstrated that his alcohol and cocaine use served self-medication purposes. Here, the goal of the intense alcohol use was not the desire to enhance creativity or productivity but to modify his normal way of functioning. Regarding the effect of alcohol upon creativity, Plucker (2009) states that moderate alcohol use affects creativity unremarkably, while heavy drinking is associated with a negative impact 
upon creativity. In a study by Brunke and Gilbert (1992), the effect of alcohol on creative writing was assessed. Eleven male social drinkers were asked to perform a creative writing task under intoxication and placebo conditions. The results showed that alcohol can ease emotional blocks while writing, although this sample was one with non-alcoholics. Kerr et al. (1991) compared the substance use of different groups of artists (writers, painters, and musicians). No significant difference was found related to substance use either among the three artistic groups or compared to the non-artist control group.

\section{Psychological effects of cannabis upon artistic creativity}

Changes in thinking and emotions have been described during intoxication including everything from euphoria to emotional suffering (Earleywine, 2002). The phenomenon of 'synesthesia' has been reported as a characteristic related to the use of psychedelic substances such as cannabis and LSD (Earleywine, 2002). There are also subjective reports that cannabis is used in order to experience a sense of liberation (Jacquette, 2010). The cannabis experience is paradoxically described as having both relaxing and stimulating nature, and provides the user with a different sensory perspective (Jacquette, 2010). Mood changes are reported to be mostly pleasurable, but sometimes anxiety, depression, and paranoia can occur (Farthing, 1992). Enhanced emotions have been reported by Tart (1971) and extreme alterations can occur depending upon the mood of the person prior to intoxication. Whether the emotions are positive or negative, they are generally felt to be more intense by the individual (Tart, 1971).

Cannabis became popular in the mid-1800s among artists in Europe. For instance, the 'Hashish Club' was founded in Paris to explore the effects of the drug by artists. Famous members included Victor Hugo, Alexandre Dumas, and Charles Baudelaire (the latter of which wrote about his experiences in the book Artificial Paradises [1860]. Although many popular writings have reported the association between cannabis use and creativity (such as its 
use by bands such as the Beatles and Rolling Stones in the 1960s), little empirical research has been carried out, and that which has been published has generated mixed findings (e.g. Kerr et al., 1991; Jones et al., 2009; Schäfer et al., 2012).

Given the lack of empirical literature, the aim of the present study was to explore the balancing role of alcohol and cannabis in the artistic creative process. More specifically, it was qualitatively examined whether these two psychoactive substances have any role in enhancement and/or relaxation it during the artistic creative process. Although other psychoactive substances can possibly be used to facilitate creativity (e.g., LSD and other psychedelic substances) it was assumed that the two most common substances used would be alcohol and cannabis based on the prevalence of using such psychoactive substances in the general population. Although the participants in the present study may have used other psychoactive substances, these were not specifically asked about. It should also be noted that polysubstance users were omitted from the study so that substance-specific effects (i.e., alcohol vs. cannabis) could be examined.

\section{METHOD}

\section{Participants}

120 artists were recruited to participate in the present study. The inclusion criterion was that all participants had to be artists by profession, or art students at one of the two Art Universities in Hungary. The artists' professions stemmed from different fields: literature, film art, fine arts, and applied arts. The artists were asked to participate on a voluntary basis and no participant received any kind of compensation. Initially, 10 artists were approached by the authors and they were asked to suggest further possible participants, who then were again asked for suggestions. The 120 participants were reached in a maximum of three steps. Of the 120 artists, 72 that had used psychoactive substances exclusively (i.e., one or the other but not 
both) were interviewed and classed into one of three groups. The Cannabis (CANN) Group $(\mathrm{N}=25)$ comprised participants who used cannabis at least twice a week during the previous year. Participants who drank alcohol either (i) more than once a week and having more than five drinks per occasion or (ii) who drank at least twenty days a month with a minimum of three drinks per occasion were assigned to the Alcohol (ALC) Group (N=18). Participants who used both cannabis and alcohol frequently or were classified as polysubstance users were excluded from the analysis so that the effects could be assigned to the specific substance. Participants in the Control Group $(C G)(\mathrm{N}=29)$ did not use cannabis during the previous year and drank alcohol (i) less frequently than on a weekly basis and having no more than four drinks per occasion or (ii) maximum twenty days a month with at most of one-two drinks per occasion.

The selected 72 participants' age ranged from 20 to 62 years. Participants of the Control Group were older (mean: 37 years, SD: 10.8) compared to the ALC group (mean: 30.6 years, SD: 6.9) and CANN group (mean: 30.9 years, SD: 9.04). Among the members of the CANN and the Control groups, the proportion of males was about two-thirds of the sample (76\% and $75.9 \%$ respectively), while in the ALC group this number was somewhat higher (83.3\%). The study was approved by the Institutional Review Board of the research team's university.

\section{Measures}

Interviews. Semi-structured face-to-face interviews of an average duration of 33 minutes were carried out with all 72 participants. The interviews were conducted as follows: the investigator briefly introduced the study, and questions about the participants' personal data (artistic background, occupation or higher education details) were asked. The interviews contained two main areas of focus. First, artists were asked about the artistic creative process, 
including how they experienced it, and what sort of special habits (if any) they had connected to it. The same questions were asked to all the participants. The artists were asked to speak freely and continuously. If they did not, additional (mostly open-ended) questions were asked by the interviewer, e.g., 'How do you create the conditions under which you work?' or 'How would you describe 'inspiration'?' In the second part, artists were asked to report directly about their opinion and experience of psychoactive substance use and its role in the artistic creative process. Similar to the first part, they were asked to speak freely and continuously. Examples of questions asked included 'Do you see any difference in the process of artistic work or in the artwork itself if you use substances or not?' and 'Have you ever worked under the influence of psychoactive substance(s)? If yes, could you describe the experience? All interviews were audio-recorded and then transcribed. Following the interviews, each participant was given a unique individual identifier that provided information about which group they were assigned to, participant number within the group, gender, and age (for instance, the fifth male participant in the Alcohol group (age: 25) was given the ID 'ALC_05_M_25'). Interviews were recorded in Hungarian and then translated into English by the authors.

Questionnaire. After each interview, a brief, structured questionnaire was administered concerning the participants' socio-demographic characteristics and their legal and illegal psychoactive substance use. Data obtained from this brief questionnaire were used to group participants using the process described in the previous section.

\section{Qualitative data analysis}

Given that the primary aim of the study was to interview participants to explore specific ways in which alcohol and cannabis are used in the creative process, content analysis was used to analyze the data_(Yang, 2008). In content analysis, text is empirically coded 
based on a coding system devised by the researchers (Babbie, 1999). In the present study, interview transcripts were content analyzed with the aim of identifying possible new aspects of the relationship (if any) between substance use and artistic creativity with a specific focus on the balancing effect (including enhancement and relaxation processes). Sentence selection of subcategories and coding were conducted by the authors. Transcripts from the three groups were content analyzed in order to document their perceptions about three phenomena. First, the relationship between the artistic creative process and various psychoactive substances are presented. Second, the relationship between the enhancement phenomenon and the use of the two psychoactive substances. Third, the relationship between the relaxation phenomenon and the use of the two psychoactive substances. References to (and opinions of) the three area of focus are emphasized with italics. These numbers of participants that mentioned these phenomena are summarized in Table 1.

\section{- - insert Table 1 here - -}

\section{RESULTS}

\section{The role of psychoactive substance use in the artistic creative process}

In relation to the use of psychoactive substances during the artistic creative process, artists had different points of views. Many participants reported that substances were used only as sources of inspiration (i.e., 9 of 18 alcohol users and 17 of 25 cannabis users, with some participants using both substances; see Table 1) while the actual implementation of the artistic work was carried out in a sober state. Others altered their state of consciousness as a way of actually facilitating work (e.g., ALC_10_M_32; CANN_06_F_31). Substance using habits varied across individuals that consumed alcohol regularly. Cannabis was reported as being used to generate and facilitate ideas. In the control group, listening to music (rather than psychoactive substance use) was reported as the most effective mind altering tool in terms of 
artistic creativity (6 out of 25; see Table 1). This most probably helps the artists to get into the state of openness which is an essential element of the creative work.

- ALC_05_M_25: "There is this heightened night state when one has drunk some glasses of wine... Then, a lot of things flow from one's brain. But obviously, I need to carry out the writing at another time and make a fair copy of it when sober ... to formulate the writing in a normal way."

- ALC_10_M_32: "I am a precise person. I need alcohol, because I know that if I drank three, four, five beers from 1 a.m. to 6 a.m. then an illuminated state comes into existence for two hours, in the good sense of the word. I am able to concentrate, focus, and experience the situation. Before that, I am too convulsive or melancholic, and after that, totally terrible. But I need that three hours a day."

- CANN_04_M_24: "Some ideas came into my mind [when smoking cannabis] but the majority of them were carried out when I was sober. The idea born in this state was very useful but in the implementation it does not help [when under the influence] ... Thoughts come earlier, the thinking process is faster but implementation is slower."

- CANN_06_F_31: "It feels like I can zoom in on the topic more, because it does not divert my attention. These weird pictures which are in my head can be liberated. At other times, when I am not high, these are of course in my head, too, but [smoking cannabis] makes it easier to realize these ideas.

- "CG_01_M_27: "During work, I usually listen to music. The kind of music depends on my mood, but I almost always listen to music. I don't know if it can be counted as the altering of consciousness, in my opinion, it might be."

- CG_06_F_41: "Music may be a psychoactive thing, because of the rhythm. Because we work with pictures, ripple, scribble. They are all rhythm and music. I like working 
with music, because I almost forget myself and the artwork will have the life of its own."

Based on the interview data, artists tended to use specific techniques to facilitate creativity although there was no clear pattern as to when such techniques were used in the creative process. Some used psychoactive substances during the initial 'inspirational' phase whereas others used them during the implementation phase. In short, there was wide variety in the nature of the relationships between substance use and the artistic creative process. No questions in the interviews concerned the use of music in the artistic creative process yet six participants in the control group mentioned music playing a facilitating role in the creative process.

\section{Substance use as an enhancement to the artistic creative process}

The use of psychoactive substances was reported by some as an enhancement technique associated with both alcohol users ( 3 of 18) and cannabis users (4 of 25; one alcohol user also reported using cannabis as an enhancer). Those who used cannabis mainly reported the disadvantage of long-term substance use. In relation to creative work, it was also reported that cannabis use might cause a loss of motivation (CANN_02_F_22) or/and inspiration (CANN_03_M_24).

- ALC_04_M_23: “And then I retreated from the world for a week [and drank alcohol]. This inspired me for about three days, but then I started to feel restless and I was not able to stay calm; it was much worse than remaining at home. So, restlessness is a small problem for me in the field of writing."

- CANN_02_F_22: “Over time, the following habit became automatic. 'OK, let's smoke a joint and the good ideas will come'. This referred not only to the creative 
process but also to a writing seminar paper or anything else. In the meantime, what really evolved was that 'I smoke a joint and after, I begin to work.' So, this became a small postponement, feeling that 'I haven't smoked enough, so I'll roll another joint... and after that, I will really begin to work',"

- CANN_03_M_24: "In my normal state of consciousness, I am not able to feel the way from where I started to where I have reached. I find this weird, it's a kind of bad feeling that possesses me that I do not really understand myself and this makes me totally nervous, because all I am creating is basically about me ... A lot of people don't have time to think this over - this means that they don't realize what the role of the used substance in the creative process is. If they took the time to think about it, they might come to realize that 'Oh, shit, I cannot work. However I also used substances'. They may then realize that they are not able to do anything and that substance use will totally block the way to inspiration."

These data demonstrate that the artists were aware of the aforementioned enhancement phenomenon. Alcohol was viewed by participants as a facilitator of the creative act with cannabis much less so.

\section{Substance use as a relaxant in the artistic creative process}

As can be seen from Table 1, alcohol was seen as a relaxant by a small minority of participants across all three groups ( 5 of 18 alcohol users; 3 of 25 cannabis users; 2 of 28 controls). Artists drink alcohol in order to get into a suitable mood for artistic creation (e.g., ALC_13_M_39). The liberating and relaxing use of cannabis was also reported in a significant minority of cannabis users (11 of 25). From another viewpoint, substance use was 
observed as part of the individual's overall behavior (CANN_12_M_40), and therefore cannot be limited only to the creative work.

- ALC_13_M_39: "In the evenings I was writing and drinking beer. It was quite good, because I could handle my restlessness with it. I felt I wish it would be finished now and I am really too bored to elaborate the details. I am not in the mood for doing it at all. Because that's what I cannot stand. And if I had drunk a bit of beer, I became more relaxed and I could work in this slightly stupid state."

- CANN_10_M_22: "Basically, it is a very liberating, cloudless feeling when I am high."

- CANN_12_M_40: "Being high is good for me especially, because in that state, I become acceptable in social situations. Then I am able to listen to other people, I don't hurry ... To be honest, I think, with the use of cannabis, I reach a level that makes me more tolerable from my usual, extremely revved state... This does not refer to creation, but to all my life. Basically, substance use is part of my personality and this can be seen in the artworks, so this is quite direct connection."

The relaxant effect of both alcohol and cannabis can clearly be seen from the interview data. The final quotation presented in this section was interesting because at this point, cannabis appeared to 'control' this particular participant's overall mood and behavior.

\section{DISCUSSION}

Looking at the data as a whole, the findings demonstrated that artists frequently report the balancing effect during artistic creation and their use of psychoactive substances (Iszáj \& Demetrovics, 2011). However, reaching a suitable psychological state for the artistic creative 
process can occur in many different ways. According to the participant's accounts, both alcohol and cannabis can function as tools in balancing the extreme emotional states that are present during the creative process. On the one hand, psychoactive substances are able to enhance tension, if necessary. On the other, if there is too much tension, psychoactive substances are reported to have a relaxant nature that reflects on Brunke and Gilbert's (1992) study where alcohol was shown to ease emotional tension. Furthermore, findings from Jacquette's (2010) study are also supported (i.e. both the enhancement and relaxant nature of cannabis was observed in the present study). During the artistic creative process, both psychological conditions appear to be essential. The heavy affective fluctuation results in artists tending to use these substances for reaching their desired psychological and/or emotional state. However, the question arises, do artists only use substances to directly aid creation or is this part of their everyday lives? In the data reported here, in some individuals, psychoactive substance use was reported to be part of the artist's overall behavior, and not only related to the creative artistic process.

Another conclusion was that the use of psychoactive substances could occur at any phase of the creative process. Based on theory outlined earlier in the present paper, it was noted that the creative process includes both an intuitive, inspirational phase and a more logical, later analytic one. The findings of the present study did not find that artists tend to use psychoactive substances more often during one of the phases. However, they used psychoactive substances to facilitate inspiration and/or to create artwork utilizing their intoxicated experiences. However, both processes can be separated from the somewhat stereotypical view on the relationship between substance use and creativity. The results of the present study suggest that artists might use psychoactive substances in order to balance their creative activity and emotional states. This more nuanced use of psychoactive substances is a different process than the more 'romantic' association between creativity and substance use. 
However, some artists thought that the actual implementation of the art should occur while sober. An interesting and unexpected observation was made in the control group where listening to music - especially rhythmic music - was described by six of the participants as a mind altering activity that they believed could aid the artistic creative process. The control group were an older group of participants (mean age 37 years - approximately seven years older than the two groups who used alcohol or cannabis). Given the fact that the control group was older and did not use psychoactive substances is probably to be expected given that drug use tends to peak in emerging adulthood and that drug use diminishes over the lifespan (Griffiths, 1996). This group may have contained more 'established' artists and were unlikely to be students any more. These participants may have used psychoactive substances earlier in their career but the data did provide any evidence relating to previous use of psychoactive substances.

The present study is not without limitations. A small self-selecting sample was examined, and therefore the generalizability of the results is limited. Furthermore, the proportion of art students versus professional artists within each group was not calculated. Consequently, the age difference between professionals and students might have played a role in psychoactive substance use. Examining the age difference within the groups should therefore be incorporated into future research studies. Another limitation was that the control group were not asked about whether they had used psychoactive substances in the past in relation to their artistic creativity. Future research should also use bigger samples and different methodologies (such as large-scale surveys) to help further examine the role that psychoactive substance use plays in the artistic creative process. 


\section{References}

Belli, S. (2009). A psychobiographical analysis of Brian Douglas Wilson: Creativity, drugs, and models of schizophrenic and affective disorders. Personality and Individual Differences, Vol. 46. 809-819.

Babbie, E. (1999). The basics of social research (8th ed.). Belmont: Wadsworth Publications.

Brunke, M. \& Gilbert, M. (1992). Alcohol and creative writing. Psychological Reports, 71, $651-658$

Cohen, S. I. (1995). Alcohol and benzodiazepines generate anxiety, panic and phobias. Journal of the Royal Society of Medicine, 88(2), 73-77.

Earleywine, M. (2002). Understanding marijuana. A new look at the scientific evidence. New York: Oxford University Press.

Ehrenzweig, A. (1970). The hidden order of art: A study in the psychology of artistic imagination. London: Paladin.

Farthing, G. W. (1992). The psychology of consciousness. New Jersey: Prentice-Hall.

Griffiths, M. D. (1996). Behavioural addictions: An issue for everybody? Journal of Workplace Learning, 8(3), 19-25.

Iszáj, F. \& Demetrovics, Zs. (2011). Balancing between sensitization and repression: The role of opium in the life and art of Edgar Allan Poe and Samuel Taylor Coleridge. Substance Use \& Misuse, 46, 1613-1618.

Iszaj, F., Griffiths, M.D. \& Demetrovics, Z. (2016). Creativity and psychoactive substance use: A systematic review. International Journal of Mental Health and Addiction. Epub ahead of print. doi: 10.1007/s11469-016-9709-8

Jacquette, D. (ed.) (2010). Cannabis. Philosophy for everyone. What were we just talking about? Chichester: Wiley-Blackwell. 
Jones, K. A., Blagrove, M. \& Parrott, A. C. (2009). Cannabis and ecstasy/ MDMA: Empirical measures of creativity in recreational users. Journal of Psychoactive Drugs. 41(4), 323329

Kerr, B. \& Shaffer, J. \& Chambers, C. \& Hallowell, K. (1991). Substance use of creatively talented adults. Journal of Creative Behavior, 25(2), 145-153.

Knafo, D. (2008). The senses grow skilled on their craving: Thoughts on creativity and addiction. Psychoanalytic Review, 95, 571-595.

Kris, E. (1939). On inspiration - Preliminary notes on emotional conditions in creative states. International Journal of Psychoanalysis, 20, 377-389.

Kris, E. (1962). Psychoanalytic explorations in art. New York, NY: International Universities Press.

Plucker, J. A. \& McNeely, A. \& Morgan, C. (2009). Controlled substance-related beliefs and use: Relationships to undergraduates' creative personality traits. Journal of Creative Behavior, 43(2), 94-101

Schäfer, G. \& Feilding, A. \& Morgan, C. J. A. \& Agathangelou, M. \& Freeman, T. P. \& Curran, H. V. (2012). Investigating the interaction between schizotypy, divergent thinking and cannabis use. Consciousness and Cognition, 21, 292-298

Sher, L. (2006). Alcohol and suicide: Neurobiological and clinical aspects. Scientific World Journal, 6, 700-706

Tart, C. T. (1971). On being stoned. A psychological study of marijuana intoxication. Palo Alto, CAL: Science and Behavior Books.

Tolson, G. H. \& Cuyjet, M. J. (2007). Jazz and substance abuse: Road to creative genius or pathway to premature death. International Journal of Law and Psychiatry 30, 530-538.

Yang, K. \& Miller, G.J. (2008). Handbook of research methods in public administration (2nd edition). New York: M. Dekker. 
Table 1. Relaxing and enhancing properties of psychoactive substance use in relation to inspiration and creativity reported by participants across all three groups (Alcohol group, $\mathbf{n = 1 8}$; Cannabis group, $\mathbf{n = 2 5}$; Control group, $\mathbf{n = 2 9}$ )

\begin{tabular}{|l|c|c|c|c|}
\hline Content & Total & Alco & Cann & Control \\
\hline Alcohol as a relaxant & 10 & 5 & 3 & 2 \\
\hline Cannabis as a relaxant & 11 & 11 & - & - \\
\hline Alcohol as an enhancer & 3 & 3 & - & - \\
\hline Cannabis as an enhancer & 5 & 1 & 4 & - \\
\hline Substances used to gain inspiration & 26 & 9 & 17 & - \\
\hline Both substances used as an inspiration & 19 & 7 & 12 & - \\
\hline Cannabis used but not in the creation process & 11 & 2 & 9 & - \\
\hline Music used as a mind altering tool & 6 & - & - & 6 \\
\hline
\end{tabular}

